\title{
TEST OF DUOPLASMATRON WITH COLD CATHODE FOR CW OPERATION
}

\author{
A. Kolomiets, B.K. Kondratiev, V.I. Turchin \\ Institute for Theoretical and Experimental Physics, Moscow, Russia
}

\begin{abstract}
Pulse duoplasmatron with cold cathode used at preinjectors of ITEP proton linacs has been tested for generation of $\mathrm{dc}$ proton beam. The operation of duoplasmatron was studied experimentally with low currents of discharge. The test bench experiments allowed to modify construction of pulsed ion source for stable dc operation with high life time. The ion source generated dc beam of protons with current $\approx 12 \mathrm{~mA}$ at $30 \mathrm{kV}$.
\end{abstract}

\section{INTRODUCTION}

Main type of the ion source (IS), using at ITEP's ion linacs, is the duoplasmatron with a cold cathode. Originally this IS was developed for I-2 linac - the ITEP proton synchrotron injector [1]. This IS showed high reliability and easy maintenance during many years. It provided operation of I-2 linac with high beam quality on its output. The amplitude of the accelerated pulse protons current from the source achieved $1 \mathrm{~A}$ with normalized emittance - $0.4-0.8 \mathrm{~cm} \cdot \mathrm{mrad}$. The same source has been used at "Istra" linac and also provided excellent quality of the pulse beam. A version of the IS with a cold cathode was used in ITEP also for production of both light and heavy ion beams with low charge state. The life time of the duoplasmatron with a cold cathode in pulse operation is determined by life time of pulse shatter installed on ion source outlet for decreasing of gas flow in the preinjector vacuum chamber and practically does not depend on cathode time operation [1].

The investigation of possibility of use the duoplasmatron with a cold cathode for direct proton beam production in framework of ITEP's feasibility study of high power linac for waste transmutation (ISTC project $\mathrm{N}$ 17) was carried out. Choice of duoplasmatron as a source for direct current beam production is caused by the following reasons: it has very simple and cheep construction; it is well studied ion source which capable to provide pulse intense proton beam with high brightness; it does not require the complicated and expensive power supply.

\section{EXPERIMENTS DESCRIPTION}

The results of study of cold cathode IS operation in pulse mode and beam parameters are given in [2]. In order to investigates operation in dc special test bench has been built. Its scheme is shown in Fig. 1. It consists of vacuum chamber (1), pumping by two turbomolecular pumps with total pumping speed $1000 \mathrm{l} / \mathrm{s}$, The operation pressure in the chamber was about $10^{-4}$ Tore.

The chamber was provided by three-electrodes ion optics system (3) made from stainless steel with $20 \mathrm{~mm}$ aperture. The optics was designed for $30 \mathrm{kV}$ extracting voltage. The electrodes of ion-optics can change their position respectively to ion source.

Current collector (2) was used for beam current measurements. It represents copper cylinder with inner diameter $90 \mathrm{~mm}$ and $30 \mathrm{~mm}$ depth. It is placed at $350 \mathrm{~mm}$ distance from ion source. The ion source installed on insulator flange (4).

In contrast to its pulsed prototype the experimental ion source has a additional cooling system for the cathode, intermediate electrode and anode. The two cylinders or multicylinders cold cathodes were installed in it. The cathodes were manufactured from molybdenum instead copper as it took place in IS I-2.

The construction of the duoplasmatron is schematically shown in Fig. 1. It consists of the copper anode (6); with outlet (7) with aperture $0.8 \mathrm{~mm}$. The intermediate electrode (8) is connected to power source (11) placed at the high voltage platform (13). The power supply (12) provides discharge current in the range from $10^{-3}$ to $5 \mathrm{~A}$. The solenoid (9) creates the magnet field in the gap between the anode - intermediate electrode. The hollow metal cold cathode (10) with gas channel is installed into the intermediate electrode. Different construction of cold cathodes could be installed in this source. The cathode voltage is fed by power source (12) placed at the high voltage platform, which potential is equal to the accelerating voltage. The voltage is supplied from the industrial high-voltage power source. The voltage can be changed from 0 to $50 \mathrm{kV}$.

The designs of the cathodes used in tests are shown in Fig. 2 and Fig. 3. The cathode shown in Fig. 2 consists of two coaxial hollow cylinders, placed at a common base. In contrast to cathode in Fig. 2 the cathode shown in Fig. 3 consists on 7 or 13 thin-walled hollow cylinders placed circularly with respect to the axis, which wall thickness and depth of hollow were determined by condition to get maximum hollow cathode effect $[3,4]$. During experiments the cathode material was varied. There were used copper or molybdenum as material for cathode. The hydrogen gas was supplied to ion source.

Thermal and radioactive loads on cathodes materials during experiments were investigated. The stability of different electric discharges was tested in dependance on cathode materials and design at direct current. Efficiency of ion generation in aria of emission was evaluated. The 
peculiarities of the ion source with cold cathode operation under steady electric arc were studied. The experiments showed that under gas pressure 1.5-2.0 Tore the arc is ignited and is stable. Maximum extraction of ions was provided. at negative voltage $280-300 \mathrm{~V}$ on intermediate electrode (8) (Fig. 1).

Current of discharge was varied in our experiment in the range 5.0 - $30.0 \mathrm{~mA}$. The current value was controlled by power supply unit (12) Fig. 1. In this case maximum current of extracted ion beam depended to a certain extent on material and construction of the cathode. The maximum ion beam current has been achieved with cathode shown in Fig. 3. This cathode consists of 13 copper cylinders. The maximum value of the proton current was $0.3 \mathrm{~mA}$ at extracted voltage $25 \mathrm{kV}$. The initial voltage applied to discharge gap was $2.0-2.2 \mathrm{kV}$. No erosion of the cathode or ion source electrodes after 30 hours of operation was observed.

Ion beam current has practically no dependence of cathode construction at discharge current $0.4-0.5 \mathrm{~A}$. The ignition of the discharge occurred at initial voltage 2.4 $2.5 \mathrm{kV}$. The steady value of discharge voltage was 500 $700 \mathrm{~V}$. This type of discharge can be considered as smolder one[4]. Under above mentioned conditions the life time of copper cathodes did not exceed 10 - 12 hours. They had remarkable destroying of the construction after this period. The cathodes made from molybdenum had no destroying after operation during the same period. The ion current $9.0-10.0 \mathrm{~mA}$ has been obtained in test experiments using molybdenum cold cathode. The construction of the cathode is shown in Fig. 2.

The installation in ion source of molybdenum cold cathode with construction shown in Fig. 2 allowed to achieve proton beam current of $12 \mathrm{~mA}$ at $30 \mathrm{kV}$ extracting voltage. The total electrical power consumption of the ion source was about $500 \mathrm{~W}$. The discharge current was very stable during all period of operation. The instability of the current value was $: \leq 5 \%$. The pressure in the vacuum chamber of test bench was $10^{-5}$ Torr.

\section{CONCLUSION}

The carried out experiments shows that duoplasmatron with cold cathode can be used for generation of intense proton beam at $\mathrm{CW}$ operation. The developed design of the source produced in experiments proton beam with current about $10 \mathrm{~mA}$ during period several tenth of hours without any damages of the source parts. Power consumption did not exceed $500 \mathrm{~W}$.

The results of experimental study of cold cathode duoplasmatron on $\mathrm{CW}$ operation allow to conclude that this type of duoplasmatron is suitable for using in CW high power linac. The advantages of this ion source are very simple and cheep mechanical design as well as power supply, stability of proton beam parameters and long life time. The main drawback of the ion source is high pressure of gas in discharge chamber and, therefore, high load on vacuum system of the preinjector.

\section{REFERENCES}

[1] V.A.Batalin, A.A. Kolomiets, B.K. Kondratiev, R.P. Kuibida, "Duoplasmatron with cold cathode", "Pribory i Technika Experimenta", N 2, 1975, p.21.

[2] B.K.Kondratiev, V.I.Turchin. "Proton source for linacs", Pre-print ITEP 51-9, 1992

[3] "Cold cathodes", Ed. M. Elinson, Sov. Radio, Moscow, 1974.

[4] V.L.Granovsky . "Electric current in gas", "Nauka", Moscow, 1971.

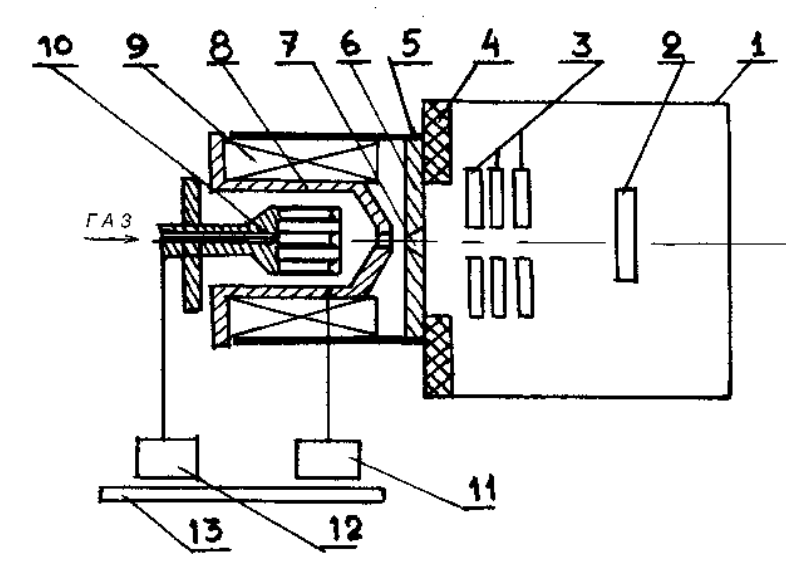

Fig.1. Sceme of IS with cold cathode and test bench

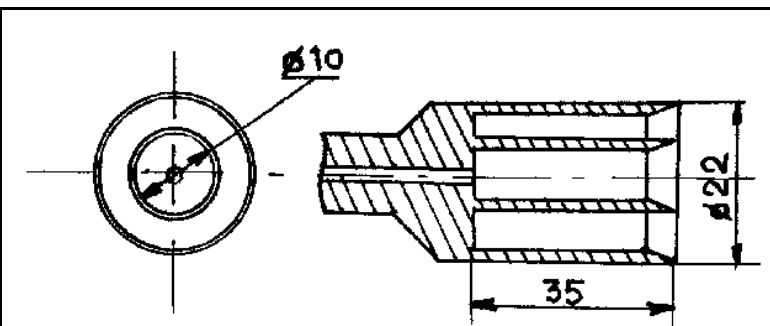

Fig. 2. Coaxial cathode

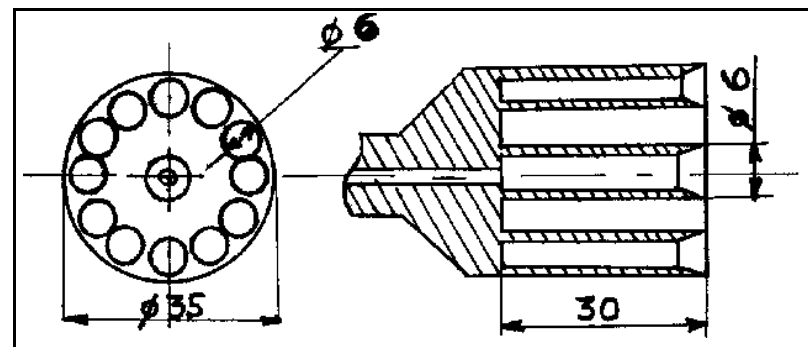

Fig.3.Multicylinder cathode 